University of Nebraska - Lincoln

DigitalCommons@University of Nebraska - Lincoln

Faculty Papers and Publications in Animal

Science

Animal Science Department

March 2001

\title{
Usefulness of subjective ovine milk scores: II. Genetic parameter estimates
}

G. D. Snowder

USDA, ARS, U.S. Sheep Experiment Station, Dubois, ID

L. Dale Van Vleck

University of Nebraska-Lincoln, dvan-vleck1@unl.edu

A. D. Knight

USDA, ARS, U.S. Sheep Experiment Station, Dubois, ID

T. R. Kellom

USDA, ARS, U.S. Sheep Experiment Station, Dubois, ID

C. M. Bromley

University of Nebraska-Lincoln

Follow this and additional works at: https://digitalcommons.unl.edu/animalscifacpub

Part of the Animal Sciences Commons

Snowder, G. D.; Van Vleck, L. Dale; Knight, A. D.; Kellom, T. R.; and Bromley, C. M., "Usefulness of subjective ovine milk scores: II. Genetic parameter estimates" (2001). Faculty Papers and Publications in Animal Science. 223.

https://digitalcommons.unl.edu/animalscifacpub/223

This Article is brought to you for free and open access by the Animal Science Department at DigitalCommons@University of Nebraska - Lincoln. It has been accepted for inclusion in Faculty Papers and Publications in Animal Science by an authorized administrator of DigitalCommons@University of Nebraska - Lincoln. 


\title{
Usefulness of subjective ovine milk scores: II. Genetic parameter estimates
}

\author{
G. D. Snowder*,1, L. D. Van Vleck $\dagger$, A. D. Knight*, T. R. Kellom*, and C. M. Bromley \\ *USDA, ARS, U.S. Sheep Experiment Station, Dubois, ID 83423; †USDA, ARS, U.S. Meat Animal Research \\ Center, Lincoln, NE 68583; and $\ddagger$ University of Nebraska, Lincoln 68583
}

\begin{abstract}
Genetic parameters for a subjective milk score given to ewes within $24 \mathrm{~h}$ of parturition were estimated to determine the usefulness of milk score as a selection trait to improve milk production, which influences total litter weight weaned. Heritability of milk score and the genetic correlation of milk score with litter weight weaned were estimated by REML separately for four sheep breeds, Rambouillet ( $\mathrm{n}=$ $1,731)$, Targhee $(\mathrm{n}=1,638)$, Columbia $(\mathrm{n}=1,731)$, and Polypay $(n=1,129)$. Litter weight weaned was the total weight of lambs weaned at approximately $120 \mathrm{~d}$ of age under a western range production system. Observed heritability estimates for milk score at first parity were moderate and similar among breeds, ranging from 0.18 to 0.32 . Heritability estimates adjusted for a binomial distribution of milk scores at first parity were high (Columbia, 0.43; Polypay, 0.35; Rambouillet, 0.50; Targhee, 0.84). Estimates of observed heritability for second-parity milk score were moderate to high, ranging from 0.23 to 0.46 . Milk score at first or second parity was genetically correlated with milk score records at
\end{abstract}

maturity (third parity and greater), with estimates ranging from 0.69 to 1.00 . Milk score and litter weight weaned were genetically correlated at first or second parity in Rambouillet $\left(r_{g}=1.00\right)$ and Targhee breeds ( $\mathrm{r}_{\mathrm{g}}=1.00$ and 0.61 , respectively), but not in the Columbia and Polypay breeds. Estimates of heritability for lifetime records for milk score ranged from 0.16 to 0.26 across breeds. Estimates of genetic correlations of annual lifetime milk score records with litter weight weaned were high (Columbia, 1.00; Polypay, 0.81; Rambouillet, 1.00; and Targhee, 0.77). Repeatability estimates for milk score were similar across breeds, 0.23 for Columbia, Rambouillet, and Targhee ewes and 0.28 for Polypay ewes. Milk score measured at first or second parity may be a good predictor of future potential milking ability. Further, milk score can be used as a selection trait to improve maternal ability for increasing litter weight weaned. The need for increasing ewe milking performance and lamb growth rate at first parity in commercial range sheep production systems may be addressed by selection for milk score at first parity.

Key Words: Ewes, Growth, Heritability, Lambs, Litter Weight, Milk

(C)2001 American Society of Animal Science. All rights reserved.

J. Anim. Sci. 2001. 79:869-876

\section{Introduction}

Preweaning survival and growth rate of lambs can be increased by improving milking performance of the ewe (Boyazoglu and Treacher, 1978; Torres-Hernandez and Hohenboken, 1980). In a companion paper, we have shown that a subjective evaluation of a lactating ewe's udder to assign a score to predict milk production (low, average, or high) was effective in classifying ewes with significant differences for lamb growth rate and total litter weight weaned (Snowder et al., 2001). Improving milking performance and lamb production of range ewes at first and second parities should result in sig-

${ }^{1}$ Correspondence: HC 62, Box 2010 (phone: 208-374-5306; fax: 208374-5582).

Received July 10, 2000.

Accepted December 7, 2000. nificant economic returns to most sheep production systems.

This study was undertaken to examine the genetic aspects of subjective milk scores on lamb production under range conditions. The first objective was to estimate heritabilities for first- and second-parity scores and the genetic correlation for milk score and litter weight weaned for first and second parities. The second objective was to estimate the genetic parameters for lifetime records of milk score and total litter weight weaned. This information is needed to determine a practical selection method for improving milking performance and lamb production in range ewes.

\section{Materials and Methods}

Records were of Rambouillet ( $\mathrm{n}=1,731$ ), Targhee ( $\mathrm{n}$ $=1,638)$, Columbia $(\mathrm{n}=1,731)$, and Polypay $(\mathrm{n}=1,129)$ ewes present in selection lines from 1977 through 1988 (three lines each of Rambouillets, Targhees, and Colum- 
bias and two lines of Polypays, each line maintained at approximately 140 mature ewes and 50 replacement ewe lambs). Genetic lines were previously described by Ercanbrack and Knight (1998). Separate analyses were conducted for each breed.

Detailed descriptions of management practices and data collection at the U.S. Sheep Experiment Station related to this study were previously reported (Snowder et al., 2001). The two traits of interest in this study were milk score and total litter weight weaned.

A subjective milk score was assigned to ewes within a few hours of parturition at the U.S. Sheep Experiment Station. A trinomial scoring system (low, average, or high) classified a ewe's expected milking potential by inspecting the udder size and fill (Snowder et al., 2001).

Total litter weight weaned was the annual sum of adjusted weaning weights of individual lambs for the ewe. Weaning weights of lambs were adjusted to a standard $120 \mathrm{~d}$ of age by multiplying the average daily gain from birth to actual day of weaning by 120 , and adding that value to the birth weight of the lamb.

Milk score was used as a management decision tool at the U.S. Sheep Experiment Station to determine the number of lambs a ewe may rear. This artificial limitation of litter size may have imposed a bias. Limiting litter size increased the probability that the lambs a ewe suckled would survive to weaning. Also, because litter size was artificially restricted to a maximum of two lambs, the implications of litter sizes greater than two on total litter weight weaned cannot be examined. Under commercial range production systems, the practice of artificially limiting litter size based on subjective evaluation of the udder and condition of the lamb(s) and ewe is common. Because the limitations imposed on this data set are typical of western range production systems, the results may only apply to similar or related production systems.

Fostering is known to affect a fostered lamb's weaning weight (Snowder and Knight, 1995). Therefore, grafted lambs as well as orphaned lambs were excluded (and their dams if no lamb was raised) from the total litter weight weaned trait. Because records of fostered lambs were deleted and not included in a ewe's litter weight weaned record, litter weight weaned records of ewes rearing a foster lamb with their own natural born lamb were accounted for by a fostering code (1 if an ewe did not foster a lamb and 2 if an ewe did foster an additional lamb) used as a fixed factor in the model for the analyses.

Estimates of genetic and environmental variance and covariance components for milk score and total litter weight weaned were obtained using a derivative-free REML algorithm (Graser et al., 1987) with the computer programs of Boldman et al. (1995). Convergence was considered to have been reached when the variance of the $-2 \log$ likelihood in the simplex was less than 1 $\times 10^{-6}$. After initial convergence, at least five restarts were performed to ensure global convergence, which was defined when the -2 log likelihood did not change to the second decimal.

The number of pedigree records, individual animal records, and sires are presented in Table 1 . The larger numbers of sires in the Rambouillet and Targhee breeds were caused by the presence of control lines randomly bred to approximately 12 sires annually, whereas selected lines were bred to four to six rams annually.

Genetic parameters were estimated for milk score and litter weight weaned based on first- or second-parity records, annual records at maturity (third parity and greater), and annual lifetime records (all parities). Because selection for milk score or litter weight weaned will most likely occur during first or second parity, (co)variance estimates were obtained between first- and second-parity scores. Estimates of (co)variance were also obtained for first- or second-parity milk scores with mature milk scores. Only ewes that lambed as yearlings or 2-yr-olds were included in first-parity analyses, and only ewes with two parities between 1 to $3 \mathrm{yr}$ of age were included in the second-parity analyses. Such interrelationships between parity and age are common in range sheep production systems. This age limitation on assignment to parity groups removed less than $6 \%$ of the total number of observations within parity groups.

Annual lifetime and mature milk score records were analyzed within breed using a repeated measures animal model. This model included the fixed effects for year of lactation (1977 to 1988), age of ewe (1 to $9 \mathrm{yr}$; mature ages were from 3 to $9 \mathrm{yr}$ ), litter size (single vs multiple), and genetic selection line (two to three lines per breed). A permanent environmental effect of the ewe was included because of her repeated measures. Milk scores at first or second parity were analyzed with a similar single- and two-trait model with the exclusion of permanent environmental effects. Estimates of the additive genetic variance for milk score were previously unknown. Therefore, prior values for the analyses were initially based on a heritability estimate of 0.25 , a value similar to an estimate for milk yield in European dairy sheep (0.29; Carriedo et al., 1995).

Repeatability of lifetime records was estimated by dividing the sum of estimates of the genetic additive and permanent environmental components of variance by the phenotypic variance.

Two-trait animal models were used to estimate the genetic correlation between milk scores at first or second parity and milk score records at mature ages. The trait-specific models were identical to those used in the single-trait analyses. The environmental covariance was held constant at zero while including the dam as a permanent environmental effect for first- or secondparity scores that had no repeated measures. The environmental correlation was calculated from the sum of the residual and permanent environmental variance components and permanent environmental covariance as detailed by Okut et al. (1999). Starting values for the genetic and environmental covariances were based on a genetic correlation of 0.60 as reported by Primitivo 
Table 1. Number of animals in pedigree, animals with records, total records, and sires of animals with records

\begin{tabular}{lcccc}
\hline \hline Breed & $\begin{array}{c}\text { Pedigree } \\
\text { records }\end{array}$ & $\begin{array}{c}\text { Individual } \\
\text { animals }\end{array}$ & $\begin{array}{c}\text { No. of } \\
\text { records }\end{array}$ & $\begin{array}{c}\text { No. of } \\
\text { sires }\end{array}$ \\
\hline Columbia & 11,096 & 1,731 & 4,769 & 267 \\
Polypay & 25,050 & 1,129 & 3,249 & 119 \\
Rambouillet & 14,418 & 1,704 & 5,336 & 434 \\
Targhee & 13,499 & 1,638 & 4,929 & 435 \\
\hline
\end{tabular}

(1986) for milk yield between first and second parities of Spanish milking sheep.

The distribution of milk scores deviated from normality. The trait was distributed as a threshold trait with a binomial (low or average) distribution at first parity and a trinomial (low, average, or high) distribution at later parities. At first parity, over $70 \%$ of the ewes were classified with low milk scores, 11 to $27 \%$ as average, and fewer than $2 \%$ as high (Snowder et al., 2001). Average milk score distributions for parities of ewes older than $2 \mathrm{yr}$ of age were 14 to $26 \%$ as low, 48 to $51 \%$ as average, and 23 to $38 \%$ as high (Snowder et al., 2001). Because there were so few ewes with a high milk score at first parity, milk score at first parity was analyzed as a single trait and considered only ewes with low or average milk scores.

Estimates of the observed heritability for milk scores were adjusted to an underlying normal distribution. Heritability estimates for first parity were adjusted (Dempster and Lerner, 1950) by multiplying the observed heritability estimate by $(\overline{\mathrm{p}} \cdot \overline{\mathrm{q}}) / \mathrm{z}^{2}$, where $\overline{\mathrm{p}}$ is the incidence of ewes with low milk scores, $\bar{q}$ (or $1-\bar{p}$ ) is the incidence of ewes with average milk scores, and $z^{2}$ is the square of the ordinate of a standard normal density function partitioning an area equal to $\overline{\mathrm{p}}$. Heritability estimates from the trinomial distribution observed for milk score at second and mature parities were adjusted (Vinson et al., 1976) to the underlying continuous scale by multiplying the observed heritability estimate by:

$$
\sigma_{\mathrm{p}}^{2} / \sum_{\mathrm{i}=1} z_{\mathrm{i}}^{2}
$$

where $\sigma_{\mathrm{p}}^{2}$ is the phenotypic variance and $\mathrm{z}_{\mathrm{i}}$ is the ordinate of a standard normal density function as previously described for each threshold. The $z_{i}^{2}$ were summed for $\mathrm{t}-1$ thresholds, where $\mathrm{t}=$ the total number of threshold classes, or 3 for the trinomial distribution.

Milk production is an important determinant of total litter weight weaned (Snowder et al., 1996). The assumption that milk score is genetically correlated to litter weight weaned was based on a previous study by Ercanbrack and Knight (1998), who reported a significant genetic improvement in milk score associated with selection for litter weight weaned in Columbia, Polypay, Rambouillet, and Targhee breeds. The genetic correlation between milk score and litter weight weaned has not been previously reported. Therefore, genetic corre- lations between lifetime milk score and litter weight weaned for the four breeds were estimated. Also, the genetic correlations between milk score and litter weight weaned at first or second parity were estimated.

Annual records for lifetime litter weight weaned were previously investigated by Bromley et al. (2000) and Hanford et al. (2000a,b,c) using data from the U.S. Sheep Experiment Station. Both studies included sheep populations from the U.S. Sheep Experiment Station that contained some records of animals that were also used in this study. A repeated measures animal model similar to that used by Hanford et al. (2000a,b,c) was used to analyze annual records for lifetime litter weight weaned. This model included fixed effects for age of ewe, year of observation, genetic line, and fostering code. Three covariates representing each sex classification of lambs within a litter (ram, ewe, wether) were included to adjust litter weight weaned for sex of the reared lambs. The covariates for sex of the lamb were expressed as a proportion of the total number of lambs weaned within the appropriate sex covariate. The sum of all covariates equaled to 1 within a litter. For example, if a ewe reared two lambs (a ram and a ewe), the values for the ram and ewe lamb covariates were both 0.5. Sire of the litter was not included in the model for litter weight weaned because it was previously reported as a nonsignificant effect on litter weight weaned in this data set and accounted for less than $1 \%$ of the phenotypic variance in all breeds (Bromley et al., 2000). A random permanent environmental effect associated with the ewe was included to model repeated records.

(Co)variance components for litter weight weaned and milk score at first or second parity were estimated with two-trait animal models using similar models and prior values from the analysis with the two-trait model for annual records for lifetime milk score and litter weight weaned. Random permanent environmental effects due to ewes were not included in models for these analyses.

\section{Results and Discussion}

Estimates of variance components from single- and two-trait models were generally similar within a trait. Therefore, only the estimates from the two-trait analyses will be reported in tables. Differences between variance component estimates from the single- and twotrait analyses greater than four units at the second decimal place will be discussed in the text. 
Investigation of first- and second-parity milk scores was based on the observations by Snowder et al. (2001) that there were large differences in the percentages of ewes assigned to the milk score classifications between 1 and $2 \mathrm{yr}$ of age. Culling ewes with low milk scores based on their own performance could potentially remove 71 to $89 \%$ of ewes at first parity but only 21 to $49 \%$ of ewes at second parity. When only considering an individual animal's own record, improvement of milking performance with increasing parity suggests that the second parity may be a better time to consider milk score than the first parity. Use of EBV for milk score including information on relatives would allow greater selection discrimination among first-lactation ewes. Significant increases in milk yield with age of the ewe up to $3 \mathrm{yr}$ have been reported in dairy sheep (Primitivo, 1986; Carriedo et al., 1995).

Estimates of (co)variance components for milk score at first and second parity from the two-trait analyses are presented in Table 2 . The phenotypic variance of milk scores was larger for second-parity than for firstparity scores. Obviously, the low phenotypic variance for first-parity scores was related to the high incidence of ewes with low milk scores (70\% or more) and very few ewes with high milk scores (0.02 to $1.6 \%)$. The estimates of additive genetic variance for milk score also increased from first parity to second parity, except in the Targhee breed. Observed heritability estimates for milk score for first and second parities were moderate (ranging from 0.18 to 0.32 ). Observed heritability estimates were similar across parities for the Columbia breed $\left(h^{2}=0.24\right)$. A previous study of dairy sheep reported that heritability estimates were the same for first- and second-parity milk yields (0.24; Primitivo, 1986). Estimates of observed heritability increased from first to second parity for Polypay and Rambouillet breeds (approximately 0.20 at first parity and 0.30 at second parity) and decreased in the Targhee breed ( 0.32 at first parity and 0.19 at second parity).

Only a few estimates of observed heritability from the two-trait model differed from those of the singletrait model. Heritability estimates from the single-trait model were smaller in the Rambouillet breed at first and second parity ( 0.11 and 0.23 , respectively). These differences were caused by slightly smaller estimates of the additive genetic variance.

Because milk scores were approximately binomially (low vs average) distributed at first parity and trinomially (low, average, or high) distributed at later parities, estimates of heritability were adjusted to an underlying standard normal distribution. Adjusted heritability estimates were larger, ranging from 0.35 to 0.84 for first parity and 0.23 to 0.46 for second parity. With the exception of the Polypay breed, adjusted heritability estimates at first parity were larger than those at second parity; therefore, response to selection for improving milk score would be greater at first parity than selection at second parity. Improving milk production at first parity rather than at second parity would be of greater economic importance (Snowder et al., 2001). Selection to improve milk scores at first parity should also consider records from relatives, because the frequency of ewes at first parity with average or high milk scores was not a sufficient number for replacement ewes under most management systems.

Genetic correlations between milk scores at first and second parity were unity for all breeds (Table 2). This correlation is higher than the genetic correlation of 0.60 reported for milk yield between first and second parities of Spanish milking sheep (Primitivo, 1986). Regardless

Table 2. Number of records (n) and estimates of (co)variance components and genetic parameters for subjective milk score at first and second parities

from bivariate analyses by breed

\begin{tabular}{|c|c|c|c|c|c|c|c|c|}
\hline \multirow[b]{2}{*}{ Parameter } & \multicolumn{2}{|c|}{ Columbia } & \multicolumn{2}{|c|}{ Polypay } & \multicolumn{2}{|c|}{ Rambouillet } & \multicolumn{2}{|c|}{ Targhee } \\
\hline & $1 \mathrm{st}$ & 2nd & $1 \mathrm{st}$ & $2 \mathrm{nd}$ & $1 \mathrm{st}$ & 2nd & $1 \mathrm{st}$ & 2nd \\
\hline $\mathrm{n}$ & 1,470 & 1,062 & 1,046 & 979 & 1,492 & 1,278 & 1,444 & 1,201 \\
\hline$\sigma_{\mathrm{a}}^{2}$ & 0.08 & 0.11 & 0.05 & 0.13 & 0.04 & 0.12 & 0.10 & 0.08 \\
\hline$\sigma_{\mathrm{e}}^{2}$ & 0.28 & 0.35 & 0.19 & 0.29 & 0.20 & 0.29 & 0.20 & 0.36 \\
\hline$\sigma_{\mathrm{p}}^{2}$ & 0.36 & 0.46 & 0.24 & 0.42 & 0.24 & 0.41 & 0.30 & 0.44 \\
\hline$h^{2}$ & 0.23 & 0.24 & 0.19 & 0.32 & 0.18 & 0.30 & 0.32 & 0.19 \\
\hline $\mathrm{h}^{2}{ }_{\mathrm{ADJ}}$ & 0.43 & 0.29 & 0.35 & 0.46 & 0.50 & 0.37 & 0.84 & 0.23 \\
\hline $\mathrm{e}^{2}$ & 0.77 & 0.76 & 0.81 & 0.69 & 0.82 & 0.70 & 0.68 & 0.81 \\
\hline$r_{g}$ & \multicolumn{2}{|c|}{1.00} & \multicolumn{2}{|c|}{1.00} & \multicolumn{2}{|c|}{1.00} & \multicolumn{2}{|c|}{1.00} \\
\hline $\mathrm{r}_{\mathrm{e}}$ & \multicolumn{2}{|c|}{0.71} & \multicolumn{2}{|c|}{1.00} & \multicolumn{2}{|c|}{-0.99} & \multicolumn{2}{|c|}{0.55} \\
\hline
\end{tabular}

${ }^{\mathrm{a}} \sigma_{\mathrm{a}}^{2}=$ Genetic variance; $\sigma_{\mathrm{e}}^{2}=$ residual variance; $\sigma_{\mathrm{p}}^{2}=$ phenotypic variance; $\mathrm{h}^{2}=$ heritability (standard errors from single-trait model were approximately 0.05 at parity $1,0.07$ at parity 2 ); $h^{2}{ }_{\mathrm{ADJ}}=$ heritability estimate adjusted to an underlying normal distribution; $\mathrm{e}^{2}=$ fraction of variance due to environmental effects; $\mathrm{r}_{\mathrm{g}}=$ direct genetic correlation between parities 1 and 2 ; and $\mathrm{r}_{\mathrm{e}}=$ environmental correlation. 
of the large differences in the distribution of phenotypic classifications for milk score between parities, the trait is genetically similar across first and second parities. Selection to increase milk score at first parity would also increase milk score at second parity, and vice versa.

Environmental correlations of milk scores at first and second parity varied among breeds. Environmental correlations for Columbia and Targhee breeds were 0.71 and 0.55 , respectively. In the Polypay breed, environmental effects on milk score between first and second parity were very highly correlated $\left(r_{e}=1.00\right)$. However, in the Rambouillet breed, there was a strong negative estimate of the environmental correlation between first- and second-parity milk scores $\left(\mathrm{r}_{\mathrm{e}}=-0.99\right)$. The strong negative environmental correlation in the Rambouillet breed may be related to the lack of sensitivity of milk score at first parity to environmental effects, as evidenced by the large percentage of Rambouillet ewes with low milk scores (89\%, Snowder et al., 2001). At second parity, there was a significant improvement in Rambouillet milk scores, and 53\% of the ewes had a milk score of average or high.

Estimates of (co)variance components for milk score at first or second parity with records at maturity are presented in Table 3. Estimates of variance components were in close agreement with those from the singletrait analyses. The phenotypic variances of milk scores at maturity were similar to those at second parity, approximately 0.46 for all breeds. Variance components due to permanent environmental effects of the ewe at maturity were small and contributed from 6 to $15 \%$ of the phenotypic variance. Observed heritability estimates for milk scores at mature ages were similar to those at second parity, with the exception of the Columbia breed. The estimate of heritability of mature milk score records of Columbia ewes was one-half that at second parity ( 0.10 vs 0.20 , respectively), caused in part by smaller estimates of genetic variance for mature records. Heritability estimates adjusted to an underlying standard normal distribution were larger compared to observed estimates of heritability. At first parity, the adjusted heritability estimates for milk score were high (0.4 for Columbia, Polypay and Rambouillet; 0.7 for Targhee). At later parities, adjusted heritability estimates were smaller and ranged from 0.13 to 0.40 . Only in the Polypay breed were adjusted heritability estimates similar across parity groups, ranging from 0.34 to 0.40 .

Estimates of genetic correlations for milk score at first or second parity with mature records were generally large (ranging from 0.69 to 1.00 ; Table 3 ). The lowest estimate of a genetic correlation, 0.69 , was between first-parity milk score and mature records for Targhee sheep. When the genetic correlation is greater than 0.80 , there is no need to consider the two traits as different traits for genetic evaluation (Robertson, 1959). First-parity milk scores for Columbia and Rambouillet breeds were very highly correlated genetically with milk score records at maturity $\left(\mathrm{r}_{\mathrm{g}}=1.00\right.$ and 0.99 ,

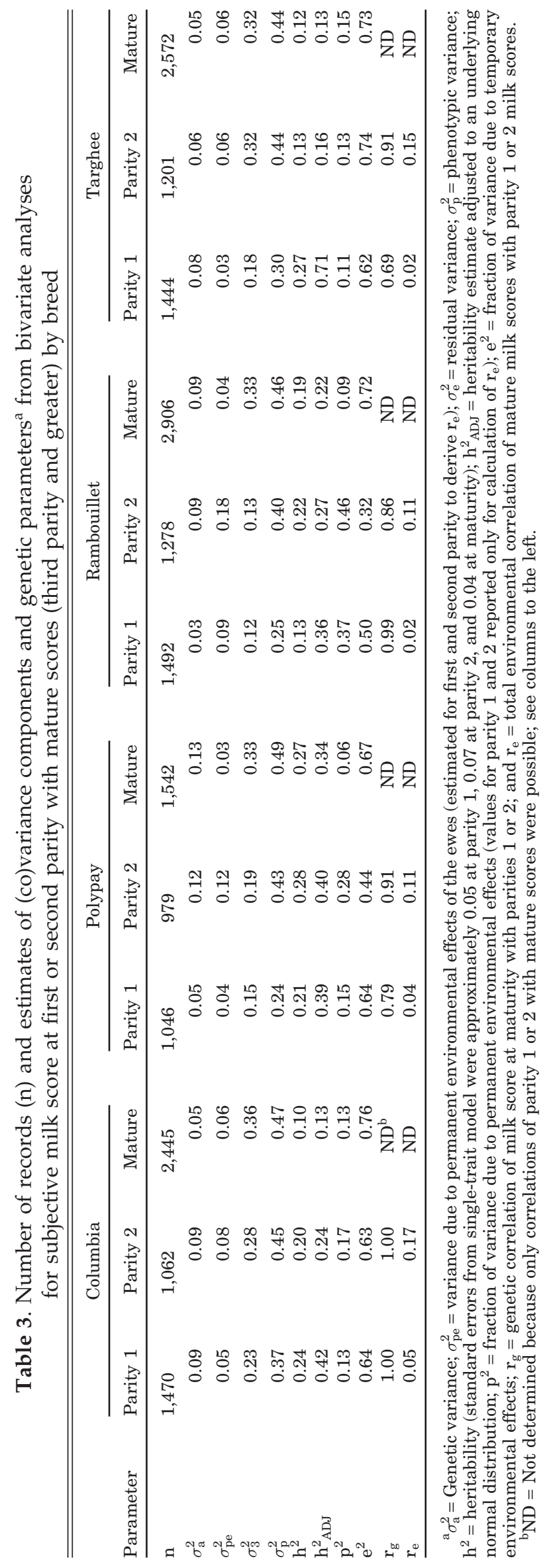


Table 4. Estimates of (co)variance components and genetic parameters ${ }^{\mathrm{a}}$ from bivariate analyses for total litter weight weaned $(\mathrm{kg})$ when analyzed with milk

score at first or second parity by breed

\begin{tabular}{|c|c|c|c|c|c|c|c|c|}
\hline \multirow[b]{2}{*}{ Parameter } & \multicolumn{2}{|c|}{ Columbia } & \multicolumn{2}{|c|}{ Polypay } & \multicolumn{2}{|c|}{ Rambouillet } & \multicolumn{2}{|c|}{ Targhee } \\
\hline & Parity 1 & Parity 2 & Parity 1 & Parity 2 & Parity 1 & Parity 2 & Parity 1 & Parity 2 \\
\hline$\sigma_{\mathrm{a}}^{2}$ & 10.51 & 0.01 & 5.89 & 19.03 & 3.44 & 2.29 & 2.88 & 4.51 \\
\hline$\sigma_{\mathrm{e}}^{2}$ & 38.12 & 91.13 & 40.69 & 85.05 & 25.64 & 70.75 & 31.22 & 65.35 \\
\hline$\sigma_{\mathrm{p}}^{2}$ & 48.63 & 91.14 & 46.58 & 104.08 & 29.08 & 73.05 & 34.10 & 69.86 \\
\hline $\mathrm{h}^{2}$ & 0.22 & 0.00 & 0.13 & 0.18 & 0.12 & 0.03 & 0.08 & 0.06 \\
\hline $\mathrm{e}^{2}$ & 0.78 & 1.00 & 0.87 & 0.82 & 0.88 & 0.97 & 0.92 & 0.94 \\
\hline$r_{\mathrm{g}}$ & 0.05 & -0.13 & 0.29 & 0.29 & 1.00 & 1.00 & 1.00 & 0.61 \\
\hline $\mathrm{r}_{\mathrm{e}}$ & 0.20 & 0.30 & 0.17 & 0.22 & 0.12 & 0.23 & 0.08 & 0.29 \\
\hline
\end{tabular}

${ }^{\mathrm{a}} \sigma_{\mathrm{a}}^{2}=$ Genetic variance; $\sigma_{\mathrm{e}}^{2}=$ residual variance; $\sigma_{\mathrm{p}}^{2}=$ phenotypic variance; $\mathrm{h}^{2}=$ heritability (standard errors from single-trait model were approximately 0.08 at parity 1 and 2 ); $\mathrm{e}^{2}=$ fraction of variance due to environmental effects; $r_{g}=$ genetic correlation for litter weight weaned and milk score at first or second parity; and $r_{e}$ $=$ environmental correlation for litter weight weaned and milk score at first or second parity.

respectively). For Polypay ewes, the estimate of genetic correlation between first-parity and mature records was 0.79. Estimates of genetic correlations for secondparity milk scores with milk scores at maturity were high ( $r_{g}$ ranging from 0.86 to1.00). Selection for milk score at first or second parity should improve milk scores at all ages.

Environmental correlations between milk score at first or second parity with mature records were small (0.02 to 0.17).

Estimates of (co)variance components and genetic parameters from the two-trait model for litter weight weaned with milk score at first or second parity are presented in Table 4. Variance components for milk score at first or second parity were similar to those with the single-trait model; therefore, only estimates for litter weight weaned are presented, including genetic and environmental correlations at first or second parity. The phenotypic variance of litter weight weaned increased from first to second parity by approximately a factor of two or greater in all breeds due to a larger average litter size at second parity (Snowder et al., 2001). Heritability estimates for litter weight weaned at first parity were low to moderate, ranging from 0.08 to 0.22 . Except for the Polypay breed, the estimate of heritability for litter weight weaned at second parity approached zero, ranging from 0.00 to 0.06 . Low estimates of heritability for litter weight weaned from analyses of multiple measures were previously reported (Ercanbrack and Knight, 1998; Bromley et al., 2000). Litter weight weaned at first or second parity was greatly influenced by environmental effects that accounted for more than $78 \%$ of the phenotypic variance in all breeds.

For the Columbia breed, milk score was not genetically correlated with litter weight weaned at first or second parity, and in the Polypay breed the estimated genetic correlation was low at first or second parity (both were 0.29; Table 4). However, very large correlations were observed in the Rambouillet $\left(r_{\mathrm{g}}=1.00\right.$ at both parities) and Targhee breeds $\left(r_{g}=1.00\right.$ and 0.61 at first and second parity, respectively). Selection for milk score at first or second parity in Rambouillet or Targhee sheep should genetically improve litter weight weaned for that parity, and presumably for later parities.

Estimates of environmental correlation between milk score and litter weight weaned were low, ranging from 0.08 to 0.30 across breeds and parities. Low environmental correlations between these two traits would be expected because milk score was measured within $24 \mathrm{~h}$ of parturition, whereas final expression of litter weight weaned was at approximately $120 \mathrm{~d}$ postpartum.

Results from bivariate analyses of annual lifetime records for milk score and litter weight are presented in Table 5. Variance components from the bivariate analyses were similar to those from the single-trait analysis. The estimated phenotypic variances of annual lifetime records for milk score were similar for all breeds but slightly less than those at second parity and for mature records (see Table 3) for all breeds. Estimates of heritability for milk score ranged from 0.16 to 0.26 and were within the ranges of heritability estimates reported at first and second parity and maturity. Similar heritability estimates were reported for milk yield in dairy sheep (ranging from 0.15 to 0.29 ; Carriedo et al., 1995).

Repeatability estimates for milk score were similar across breeds, 0.23 for Columbia, Rambouillet, and Targhee ewes and 0.28 for Polypay ewes. Repeatability estimates for milk yield in Spanish Churra dairy sheep were reported to be slightly higher (0.32 to 0.43; Carriedo et al., 1995).

Phenotypic variances of annual lifetime records for litter weight weaned were approximately the same as those reported for the second parity, except for the Polypay breed, which had a second-parity phenotypic variance $22 \%$ larger than the variance of annual lifetime records. Heritability estimates for lifetime records for litter weight weaned were low, ranging from 0.06 to 0.15 . Similar heritability estimates for annual lifetime 
records for litter weight weaned have been previously reported (Hanford et al., 2000a,b,c).

Estimates of genetic correlation of annual lifetime records for milk score and litter weight weaned were generally large, ranging from 0.74 to 1.00 . These traits can be considered genetically similar in the Columbia, Polypay, and Rambouillet breeds $\left(\mathrm{r}_{\mathrm{g}}=1.00\right)$. In the Targhee breed this correlation was large (0.74). Selection on either one of these traits would result in genetic improvement of the other one. Selection for lifetime production for litter weight weaned in Targhee ewes increased milk yield of a 112-d lactation period by $13 \%$ compared to randomly bred control ewes (Head et al., 1995).

Except in the Rambouillet, permanent environmental correlations of milk score with litter weight weaned were near zero. The null permanent environmental correlation implies that in these breeds the ewe does not carry any important common permanent environmental effects on these two traits. The Rambouillet breed had an estimated permanent environmental correlation of 1.00 between these traits.

The environmental correlations from the analysis of annual lifetime records for milk score and litter weight weaned were near zero for all breeds. Again, this result is most likely due to the large time span between the measurement of milk score and litter weight weaned during the rearing of a range lamb ( 1 to $d 120$ ).

Milk score has practical value for improving lamb production in western range sheep under the produc- tion system studied. Litter weight weaned could be improved by selecting for improved milk score because of the high genetic correlation between the two traits and the high heritability estimate for milk score. The merit of indirect selection for litter weight weaned can be defined as the ratio of the expected correlated response when selecting for improved milk score to the expected response from direct selection for litter weight weaned (Falconer, 1989). This ratio, expressed as a percentage, varied among breeds (Columbia, 7\%; Polypay, 47\%; Rambouillet, 205\%; and Targhee, 325\%) when selection was based on first-parity performance and heritability estimates adjusted to the underlying normal scale. If selection were based on milk records at maturity, this ratio would be very favorable for Columbia, Polypay, and Rambouillet breeds $(163,125$, and $141 \%$, respectively) but less so for Targhee (79\%). Selection for milk score should improve litter weight weaned for all breeds, with the exception of the Columbia breed using first-parity milk scores.

Even in purebred flocks for which records on litter weight weaned are available, selection for milk score may result in greater response for litter weight weaned than selecting directly for litter weight weaned. In commercial flocks for which records for litter weight weaned are not commonly available, producers may improve litter weight weaned by selecting and culling commercial replacement ewes based on milk score. Selection based on annual lifetime records for milk score would improve lifetime records for litter weight weaned.

Table 5. Number of observations (n) and estimates of (co)variance components and genetic parameters ${ }^{\mathrm{a}}$ from bivariate analyses for all annual records in a lifetime for subjective milk score with annual records for total litter weight weaned $(\mathrm{kg})$ by breed

\begin{tabular}{|c|c|c|c|c|c|c|c|c|}
\hline Item & \multicolumn{2}{|c|}{ Columbia } & \multicolumn{2}{|c|}{ Polypay } & \multicolumn{2}{|c|}{ Rambouillet } & \multicolumn{2}{|c|}{ Targhee } \\
\hline \multicolumn{9}{|l|}{ Parameter } \\
\hline $\mathrm{n}$ & \multicolumn{2}{|c|}{4,769} & \multicolumn{2}{|c|}{3,249} & \multicolumn{2}{|c|}{5,336} & \multicolumn{2}{|c|}{4,929} \\
\hline$\sigma_{\mathrm{a}}^{2}$ & 0.07 & 5.12 & 0.10 & 9.36 & 0.06 & 6.31 & 0.07 & 11.09 \\
\hline$\sigma_{\mathrm{p}}^{2}$ & 0.43 & 86.79 & 0.40 & 84.99 & 0.39 & 75.55 & 0.40 & 73.64 \\
\hline $\mathrm{h}^{2}$ & 0.16 & 0.06 & 0.26 & 0.11 & 0.16 & 0.08 & 0.17 & 0.15 \\
\hline $\mathrm{p}^{2}$ & 0.07 & 0.00 & 0.02 & 0.01 & 0.07 & 0.10 & 0.06 & 0.02 \\
\hline $\mathrm{e}^{2}$ & 0.77 & 0.94 & 0.72 & 0.88 & 0.77 & 0.82 & 0.77 & 0.83 \\
\hline $\mathrm{r}_{\mathrm{p}}$ & \multicolumn{2}{|c|}{0.00} & \multicolumn{2}{|c|}{0.00} & \multicolumn{2}{|c|}{1.00} & \multicolumn{2}{|c|}{0.00} \\
\hline $\mathrm{r}_{\mathrm{e}}$ & \multicolumn{2}{|c|}{0.00} & \multicolumn{2}{|c|}{0.00} & \multicolumn{2}{|c|}{0.00} & \multicolumn{2}{|c|}{0.00} \\
\hline
\end{tabular}

${ }_{\mathrm{a}}^{\mathrm{a}} \sigma_{\mathrm{a}}^{2}=$ Genetic variance; $\sigma_{\mathrm{pe}}^{2}=$ variance due to permanent environmental effects of the ewes; $\sigma_{\mathrm{e}}^{2}=$ residual variance; $\sigma_{\mathrm{p}}^{2}=$ phenotypic variance; $\mathrm{h}^{2}=$ heritability (standard errors from single-trait model were approximately 0.04 for milk score and 0.03 for litter weight weaned); $\mathrm{p}^{2}=$ fraction of variance due to permanent environmental effects; and $\mathrm{e}^{2}=$ fraction of variance due to environmental effects. Repeatability $=$ sum of $h^{2}$ and $p^{2} ; r_{g}=$ genetic correlation; $r_{p}=$ permanent environmental correlation; and $r_{e}=$ temporary environmental correlation. 
Higher heritability estimates for milk score at first or second parity or annual lifetime records compared to litter weight weaned, the large genetic correlations between milk score and litter weight weaned, and the ease of measurement of milk score combine to suggest that milk score may be the most useful trait for increasing ewe productivity for lamb production.

\section{Implications}

A reliable trait to predict milking ability as related to a ewe's productivity for litter weight weaned has not been previously available for commercial range and purebred sheep. The subjective measure of milk score based on udder condition early postpartum has been shown to be phenotypically and genetically related to ewe productivity for litter weight weaned. Selection for milk score at early parities or based on lifetime records would result in favorable improvement in milk scores and litter weight weaned. A common production concern for low milk production at first parity and light litter weight weaned can be addressed by selection for milk score. Lifetime productivity for litter weight weaned can also be improved by selecting for lifetime records of milk score. Producers should consider incorporation of milk score into their management and selection schemes.

\section{Literature Cited}

Boldman, K. G., L. A. Kriese, L. D. Van Vleck, C. P. Van Tassell, and S. D. Kachman. 1995. A Manual for Use of MTDFREML. A set of programs to obtain estimates of variances and covariances. USDA, ARS, Clay Center, NE.

Boyazoglu, J. G., and T. T. Treacher. 1978. Milk production in the ewe. In: J. G. Boyazoglu and T. T. Treacher (ed.) Proc. Sheep and Goat Commission of the Eur. Assoc. Anim. Prod. Eur. Assoc. Anim. Prod. Publ. No. 23, Brussels.

Bromley, C. M., G. D. Snowder, and L. D. Van Vleck. 2000. Genetic parameters among weight, prolificacy, and wool traits of Columbia, Polypay, Rambouillet, and Targhee sheep. J. Anim. Sci. 78:846-858

Carriedo, J. A., J. A. Baro, L. F. de la Fuente, and F. san Primitivo. 1995. Genetic parameters for milk yield in dairy sheep. J. Anim. Breed. Genet. 112:59-63.
Dempster, E. R., and I. M. Lerner. 1950. Heritability of threshold characters. Genetics 35:212-236.

Ercanbrack, S. K., and A. D. Knight. 1998. Responses to various selection protocols for lamb production in Rambouillet, Targhee, Columbia, and Polypay sheep. J. Anim. Sci. 76:1311-1325.

Falconer, D. S. 1989. Introduction to Quantitative Genetics. 3rd ed. John Wiley \& Sons, New York.

Graser, H.-U., S. P. Smith, and B. Tier. 1987. A derivative-free approach for estimating variance components in animal models by restricted maximum likelihood. J. Anim. Sci. 64:1362-1370.

Hanford, K. J., G. D. Snowder, and L. D. Van Vleck. 2000a. Genetic parameter estimates for prolificacy, growth and fleece characteristics in Targhee sheep. J. Anim. Sci. 78(Suppl. 1):70 (Abstr.).

Hanford, K. J., G. D. Snowder, and L. D. Van Vleck. 2000b. Genetic parameters for prolificacy, growth and fleece characteristics in Columbia sheep. J. Anim. Sci. 78(Suppl. 1):71 (Abstr.).

Hanford, K. J., L. D. Van Vleck, and G. D. Snowder. 2000c. Genetic parameter estimates for prolificacy, growth and fleece characteristics in Polypay sheep. J. Anim. Sci. 78(Suppl. 1):31 (Abstr.).

Head, W. A., P. G. Hatfield, J. A. Fitzgerald, D. M. Hallford, M. K. Petersen, and J. N. Stellflug. 1995. Effects of lifetime selection for kilograms of lamb weaned per ewe on ewe milk production, ewe and lamb feed intake and body weight change. Sheep Goat Res. J. 11:78-83.

Okut, H., C. M. Bromley, L. D. Van Vleck, and G. D. Snowder. 1999. Genotypic Expression at Different Ages: I. Prolificacy traits of sheep. J. Anim. Sci. 77:2357-2365.

Primitivo, F. San. 1986. Milk production sheep breeding. In: Proc. U.S.-Spain Joint Seminar on Sheep Breeding, Zaragoza, Spain. pp 226-235.

Robertson, A. 1959. The sampling variance of the genetic correlation coefficient. Biometrics 15:469-485.

Snowder, G. D., P. G. Hatfield, and A. D. Knight. 1996. Composite trait selection for lamb production. In: Proc. National Sheep Genetics Symp., Columbus, OH. Am. Sheep Ind. Assoc., Engelwood, CO. pp 137-144.

Snowder, G. D., and A. D. Knight. 1995. Breed effects of foster lamb and foster dam on lamb viability and growth. J. Anim. Sci. 73:1559-1566.

Snowder, G. D., A. D. Knight, L. D. Van Vleck, C. M. Bromley, and T. R. Kellom. 2001. Usefulness of subjective ovine milk scores: I. Associations with range ewe characteristics and lamb production. J. Anim. Sci. 79:811-818.

Torres-Hernandez, G., and W. Hohenboken. 1980. Relationship between ewe milk production and composition and preweaning lamb weight gain. J. Anim. Sci. 50:597-603.

Vinson, W. E., J. M. White, and R. H. Kliewer. 1976. Overall classification as a selection criterion for improving categorically scored components of type in Holsteins. J. Dairy Sci. 59:2104-2114. 